\title{
Emoticons: Between Linguistic Innovation and Symptom of the Posthuman Era
}

\author{
Robert CINCU, PhDc \\ Faculty of Letters, Babeș-Bolyai University of Cluj-Napoca \\ E-mail: robertcincu@yahoo.com
}

\begin{abstract}
The paper focuses on the topic of online communication, determining a series of mutations that this type of discourse has brought to the larger context of communication in general. My aim is to point out the fact that some aspects specific to online communication (the use of emoticons, for example) correspond to what is known (in contemporary cultural studies) as a posthuman shift in discourse.
\end{abstract}

Keywords: posthuman, emoticon, language, online communication, internet.

The purpose of this paper is to point out the fact that several features specific to online communication correspond to what contemporary cultural studies refer to as a posthuman shift in discourse. The differences between communication in general and online communication have often been debated, especially in the field of linguistics, and many theorists have pointed out several differences, but also similarities, between the two. I will not be focusing on such debates here, since my aim is oriented towards formulating an adequate contextualization of online communication, rather than establishing its functional principles in relation to communication in general. Thus, I will be analyzing some of the specific innovations of online communication within a theoretical framework that proves to be not only compatible, but quite essential to the understanding of these mutations.

In the past few years, when referring to contemporary culture or society, theorists had proposed a concept - that of posthumanism - and the concept is gain- 
ing an ever growing visibility in this filed. In other words, after the world (or, at least, Western culture) has witnessed a classical era, a modern and a postmodern one, it seems that today, at a global level, we are entering the first stages of a major cultural paradigm: that of poshumanism. This cultural and social shift corresponds, in fact, to another massive change that is of great importance in contemporary geology: according to geologists, the Earth seems to have recently entered into an era which can be best described as the Anthropocene. To summarize, geologists have noticed the fact the man's intervention (and presence) on Earth was so significant that today these interventions made by man throughout time are the most relevant indicators for geological studies. Therefore, both geology and cultural studies seem to be giving an immense attention to the topic of man, mankind/humanity, in an unprecedented manner. There are, of course, numerous reasons for this intense focus on the human being, and some of them shall be discussed in this paper, however, what I wanted to point out at this stage is not the fact that posthumanism is important in today's theoretical studies, but rather the fact that (the concept of) humanity is witnessing a broad reinterpretation/redefinition, and some of the conclusions that theorists have reached are directly related to human communication. In fact, the way people communicate in contemporary society validates even more the need for a better clarification of the posthuman paradigm. Thus, in the following paragraphs I will discuss some of the features that define posthumanism according to several theorists specialized in this matter. Afterwards, I shall point out that online communication (or human communication "enhanced" by technology) corresponds entirely to the posthuman shift, and therefore, an analysis of online communication and its features should take into consideration this new paradigm of posthumanism as a theoretical framework, even though we are dealing with a concept that is highly debated and has not yet been completely clarified. Obviously, since we are witnessing what seems to be only the first stage of posthumanism, a broader description of the concept is, for now, inaccessible, leaving, eventually, only the possibility of formulating speculations that might prove to be relevant (or not) in the next years.

One of the first and major contributions to the posthuman debate is related to N. Katherine Hayles' book, How We Became Posthuman. The author here clearly formulates most of her observations concerning the posthuman paradigm in relation to the ever-growing technological development, approaching subjects such as cybernetic anxiety, virtual bodies, narratives of artificial life, etc. (Hayles, 1999). However, it is the obvious that not all aspects concerning internet or artificial intelligence can be related to the concept of posthumanism, because in this case we would be dealing with another concept, that of digital culture, and digital culture, in general, is commonly associated to postmodernism (the "previous" major cultural paradigm). Therefore, as recent works have shown, posthumanism mostly 
describes those aspects of human culture and society that challenge our traditional understanding of the concept of "human". In other words, if machines were initially designed to replace human work (as was the initial purpose of the industrial revolution), in the past years technological development has reached such a stage that permits us to talk about machines (or technology, in general) that replace not only human work, but also parts of human communication (online chatting), human relationships (social media), human organs (Human Enhancement Technologies), etc. Of course, many of these technological innovations have an enormous contribution to the development of human society, and most posthuman theorists acknowledge their importance. However, as technology begins to take over more and more aspects of human life, from a philosophical point of view some theorists have raised a question concerning the nature of "humans" in contemporary society. If mankind is massively contaminated by technology, should we redefine our understanding of "humans" in general?

A very interesting solution to this debate is proposed by theorist Rosi Braidotti, who claims that the concept of "human" can no longer be isolated within its traditional limits, proposing a broader and, in a sense, challenging view on this topic: "the relationship between the human and the Technological Other has changed in the actual context, reaching a level of intrusion and intimacy unseen before. The posthuman dilemma forces a shifting of the limits between structural differences or ontological categories such as organic and inorganic, born and made, meat and metal, electronic circuits and organic nervous systems. [...] the main success of the microelectronic seduction is, in fact, neuronal, in the sense that it brings forward the fusion between human conscience and the general electronic network" 1 (Braidotti, 2016, p. 120-121). In such a context in which man uses machines for more and more of his activities, a feeling of alienation is inevitable, and a posthuman approach usually solves the problem of alienation in two ways: 1) either we give up the massive use of technology, regaining our traditional "human" features or 2) we accept the fact that "man" is now a term that has changed its meaning and that massive technological contamination is just an evolutionary step of mankind. It is also important to note here the fact that not only technology is responsible for this cultural crisis of the concept of "humanity". As Romanian theorist Radu Vancu demonstrates, Western culture has suffered a cultural (and social) process of massive de-humanization, due mainly to Modernism (a project explicitly oriented towards challenging the traditional understanding of "human"), and it is only recently that we can talk about a cultural process of re-humanization, an attempt to recover a certain coherence that Western culture seems to have lost concerning its

1 All quotations in this paper (of other languages) have been directly translated into English by the author, Robert Cincu. 
understanding of mankind (Vancu, 2016). Also, Radu Vancu points out the fact that the French philosopher Michel Foucault had proposed and argued several decades ago a (famous) theory concerning "the death of man". Therefore, if we accept Foucault's theory concerning the (symbolic) death of man, then we find another reason, of chronological relevance, to discuss about present society in terms of post-humanism. After man has given up most of his essential features, remaining unrecognizable by his own standards, the question of a new man arises, or at least, a question of regaining the old man, and such debates usually populate the rather recent field of posthuman studies.

Another important aspect that must be noted here is the fact that theorists (Pepperell, 2003) have observed that, from a posthuman point of view, technological innovations might seem extremely new, while they are actually performing functions specific to mankind for ages. This is in fact one of the problems with technology in general, since in many cases it provides an impression of novelty, appealing to the individual, while performing a very simple and familiar function. Finally, it is also important to mention the fact that in literature, or in the arts generally speaking, posthumanism is often associated with a (post)apocalyptic scenery, and this aspect is also of some importance concerning the subject of this paper.

Of course, in these short paragraphs above I have pointed out just a few features specific to contemporary posthuman debates, and I shall proceed in the next part of my study to discussing aspects of online communication, and especially the use of emoticons, in relation to this posthuman paradigm.

The massive use of internet by the general population is, by many standards, a recent phenomenon. It is only in the last two decades that we can talk about an exponential growth concerning internet use related to the number of individuals using it, the vast geographical range of its use or in relation to the multiple features/ programs that people work with (Buckley \& Clark, 2009). Concerning the topic of this paper the online chatting phenomenon is most important, and here I am referring to all types of messenger-like programs that allow individuals to communicate via internet in real time (yahoo messenger, facebook messenger, mirc32, etc.), permitting the individual to have a conversation with his peers not face to face (in the physical presence of each other), but online (in the physical absence of each other). Of course, this feature is not specific only to internet communication, the telephone, for example, permitting a similar type of distant conversation. What is important, however, is the fact that online chatting has generated, shortly after is massive use by the general population, a series of linguistic elements specific to it, and it is these elements that can be symptomatic for the posthuman shift in discourse.

Since online chatting is based on typing, and since it permits real-time responses from the individuals chatting, it has generated the need to type faster and, with relevance to this paper, certain solutions that had become standardized throughout time can be very interesting. It is the case of emoticons, of course, a combina- 
tion of punctuation signs that generates a certain meaning. Some of the common examples include: “:)" represents smiling, while “:))" would symbolize laughing, ":(" for being sad, etc. However, the examples I have given here are not yet emoticons. These types of combinations of punctuation signs were used mainly in older programs of online chatting (like mirc32, for example), and they would appear on screen in the same way as they were typed (as combinations of punctuation signs), symbolically representing a certain emotion. Even though the meanings of these combinations of punctuation signs have been standardized, in the sense that most participants in online conversation know the fact that ":)" represents a smile and communicate according to these rules, a new standardization has been made by more recent programs of online chatting, a graphic one. To be more specific, when typing a certain combination of signs in a chat box of a more recent program (such as facebook messenger or yahoo messenger, etc.), the computer screen does not show the combination of signs, but shows instead an image of a (usually) yellow face that is smiling, or crying, depending on the combination of signs typed. These images, entitled emoticons, are standardized images that reproduce human expressions in order to make it easier for the user to type (his emotions).

I have already pointed out the fact that from a posthuman perspective (but not limited to this perspective), certain technological innovations might seem extremely new, while performing a functional involution. It is also the case with emoticons, at least from a linguistic point of view. If we take into consideration the philosophy of signs developed by Charles Sanders Peirce it is quite easy to determine the fact that emoticons (just as their name suggests) are iconic signs (Peirce, 1978). Their meaning is derived from their resemblance to something that we can find in real life, that something being human expressions. In other words, a smiley face emoticon signifies "a smiling face", and imitates (in a standardized graphic form) that specific human expression. Most words, on the other hand, are, according to Peirce, symbols (there is no resemblance between the word "rabbit", for example, and the small white mammal that likes to eat carrots). Also, each language provides a different symbol (word) for the same object, not based on a common physical feature, but as a simple convention with symbolic function. From this point of view, emoticons seem to resemble the ancient hieroglyphs, more than they resemble contemporary written language. Since hieroglyphs were partially based on their iconic relevance, their use was rather limited and throughout time their iconic functions started shifting towards a symbolic function. In other words, contemporary writing (with letters generating symbolic words that designate certain objects) is an evolved form of writing, yet the use of emoticons in online chatting seems to prefer this functional involution of writing, returning to the limited iconic signs that lack expressivity, but permit (due to the computer) a faster transfer of (standardized, inexpressive) meaning. 
The fact that emoticons seem to introduce a new revolutionary feature in (online) communication is powerfully balanced by the fact that this innovation is, in fact, not new, not revolutionary and, by many standards, it sets back writing to a series of ancient principles that have been proven to be highly limited, in comparison to contemporary forms of writing. Of course, the linguistic aspects mentioned here do not exclude the fact that emoticons have brought certain advantages as far as online chatting in concerned (a simplification of emotion expression in writing being just one of them), however their advantages do not exclude the fact that massive use of emoticons (in online conversation by people all over the word on a day-to-day basis) can be seen as a posthuman symptom.

The use of emoticons does not exclude the use of common writing in all its forms therefore they cannot be seen as (exclusive) substitutions for other linguistic elements. Rather, they can be seen as an infiltration of technological development inside human discourse. Emoticons are part of day-to-day human conversation just as much as words like "thank you", "please", "goodbye", etc. in some cases. The odd thing regarding these emoticons, however, is the fact that they are (mainly) computer-dependent. A man can smile without a computer, but it is rather rare that a man should use an emoticon without a computer, smartphone, PCtablet, etc. Thus, the posthuman feature of these emoticons is not necessarily the fact that they exist or that people use them, it is the fact that they are an infiltration in human discourse used at a mass level on a day-to-day basis even though they are of electronic nature. To simplify, emoticons are not words, even though their use in online communication is similar to that of words, they are not sentences (although their meaning can be reduced to a sentence), they are not pictures of something (but rather a standard sketch of a certain human expression), and their use is mainly oriented towards online communication (since they are primarily of digital nature).

If we take a look at any recent list of emoticons we can also observe the fact that there are more and more such emoticons, covering a wider range of human emotions/expressions. This list itself has a certain posthuman relevancy, especially from the artistic point of view. I have mentioned earlier the fact that in literature, for example, recent posthuman texts often reveal a post-apocalyptic scenery. The list of emoticons that people can use today in their conversations has developed so much that we can, in fact, talk about an archive of human expressions and the simple existence of such an archive raises the most interesting questions regarding the need, the use, the nature and, most importantly, the purpose of this ever growing list. It is almost certain that the permanent development of new emoticons does not improve online communication, since the most used emoticon today remains the original smiley face. Rather, it seems that new emoticons are created in a viruslike manner, only for the purpose of developing their number, ignoring any func- 
tional purposes, with the only difference that this spreading virus of developing emoticons does not affect the internet so much, but rather its users, since they have adopted emoticons as a daily linguistic routine.

The aspect of appearing new and innovative (because it is online), while functioning according to archaic principles is not a feature specific only to emoticons, but rather to the entire online context in which they are produced. From this point of view, emoticons only carry on features that are, in fact, specific to the online environment in general. Most pages that can be accessed online, for example, are of archaic functionality also and, as author Mircea Cărtărescu observes, the "new" that the online environment brings is most of the times very "old": "before books, there was the papyrus, as you know. They were hard to handle because you had to unfold them all the time [...] the invention of the codex, or the book as we know it today, was an extraordinary progress. The computer has returned to the papyrus, the scroll. To read a computer screen you have to scroll all the time. It's clumsy, it's not good for the act of reading" (Cărtărescu \& Cesereanu, 2016, p. 34). Cărtărescu's observation mentioned here is very interesting regarding the topic of this paper if we also take into consideration the fact the many ancient scrolls (papyrus) were inscribed with hieroglyphs. Therefore, a computer screen today that displays a certain conversation in a scroll-like manner, populated with emoticons can seem, for good reasons, innovative, even though functionally we are dealing with an ancient organization of text, that has been proven to be inferior to the contemporary system of writing.

Other examples, of an even more recent occurrence in the online environment, seem to preserve this unusual balance between the impression of novelty and the archaic functionality. The "memes" phenomenon (pictures with written text on them that visually and textually formulate a certain funny, profound, poetic idea), mainly associated to the facebook platform, shares the same characteristic (alongside the several facebook pages associated to it), as theorist Isaac Ionescu observes: "this digital revolution indicates the formation of a cultural bubble that is gradually taking distance from the conventional written culture while moving towards a culture of the anonymous - collective author, towards a cultural product with a mobile content and unknown origins: a phantasmal return to oral culture" (Ionescu, 2016). Just like the ancient writings, oral culture, or folklore in general, is functionally dependent on archaic principles and today we are witnessing the resurrection of these features in a digital environment that has become a daily occurrence in the life of most individuals.

To summarize, the appearance of emoticons (in their graphic standard form) is clearly a result of massive online communication performed by individuals around the world in the last two decades. From a linguistic point of view, these emoticons prove to be both new acquisitions to human discourse and old linguis- 
tic signs, as far as their functionality is concerned. However, the fact that they are of digital nature (a computer archive of standardized human expressions) makes their contribution to human discourse seem like a technological contamination, possibly one of the first ever produced at such a mess level, with such a frequent usage. Human discourse, on the other hand, is, without a doubt, essential in relation to a traditional definition of "human". Therefore, this digital contribution to human discourse could challenge our traditional understanding of the concept of "human", and the theoretical instruments necessary for the solving of this issue are, in fact, common to posthuman studies. Regardless of debates that try to determine if such a linguistic acquisition is "good" or "bad", the phenomenon is mainly important in a theoretical effort to determine specific changes in contemporary society, and, from this point of view, a digital contamination of human discourse could be an excellent indicator for the type of specific changes that recent society has adopted. In other words, a study on the nature, use and purposes of emoticons could bring a significant contribution to the field of posthuman studies, but also the field of posthuman studies itself could provide excellent theoretical framework for a broader analysis of emoticons, clarifying social and cultural aspects that traditional linguistics could fail to deliver (due to its lack of interest in such features). Finally, being of recent massive usage and also being of digital nature, emoticons share common features with many of the technological innovations of recent times and this aspect makes them symptomatic for the broader register of posthuman changes in contemporary society.

\section{References}

1. Braidotti, R. (2016), Postumanul (The Posthuman). Romanian translation: Ovidiu Anemțoaicei. Bucharest: Hecate.

2. Buckley, P., \& Clark D. (2009). Internet. Bucharest: Litera International.

3. Cărtărescu, M., \& Cesereanu, R. (2016). Cititorul este eroul literaturii (The Reader is Literature's Hero). Steaua, 11-12, 33-38.

4. Hayles, N. K. (1999). How We Became Posthuman. Chicago \& London: The University of Chicago Press.

5. Ionescu, I. (2016). Memetastază. Un studiu critic despre contracultură în umorul internautic românesc (Meme-metastasis. A Critical Study on Counterculture in Romanian Internet Humour). Retrieved from https://revistavatra.org/2016/11/19/ isaac-ionescu-memetastaza-un-studiu-critic-despre-contracultura-in-umorul-internautic-romanesc.

6. Peirce, C.S. (1978). Écrits sur le signe. Rassemblés, traduits et commentés par Gérard Deledalle. Paris: Éditions du Seuil.

7. Pepperell, R. (2003). The Posthuman Condition. Bristol: Intellect Books.

8. Vancu, R. (2016). Elegie pentru uman (Elegy for the Human). Bucharest: Humanitas. 